\title{
Can Neurologists Come from Behind and Lead the Way in Physician Gender Equity?
}

\author{
Julie K. Silver, MD
}

$\mathbf{N}$ EUROLOGISTS ARE PHYSICIANS who have made a commitment to solving complicated medical problems that involve our intricate nervous system, and there is no doubt that they are deserving of our respect as intellectuals in a sea of highly trained physicians. Specifically, neurologists are experts in conscious and unconscious movements, behaviors, and thought patterns. Therefore, explicit (conscious) and implicit (unconscious) workforce gender biases are topics that neurologists seemingly would be very familiar with and able to actively and successfully address. However, despite physician competence in tackling difficult problems, the specialty of neurology has been repeatedly cited in the literature as having serious physician gender equity issues. Graves and Brashear wrote, "...recent data in Neurology show that we lag behind the rest of medicine with continued gender disparities." ${ }^{1}$ For example, the American Academy of Neurology (AAN) has had only one female president in its history, ${ }^{1}$ and women have been underrepresented among recipients of AAN recognition awards. ${ }^{2}$ Given this information, I pose an interesting question to leaders and physicians in neurology: Can neurologists come from behind and lead the way in addressing and achieving physician gender equity? After all, workforce disparities for women in neurology almost certainly play some role in physician burnout-which is higher in neurology than in other specialties $^{3-5}$-and attrition, as well as negatively impact patient care and research. The stakes are high, and neurologists have a distinct opportunity to accelerate the pace of their gender equity efforts.

In this issue, Moore et al. ${ }^{6}$ analyzed responses to an online survey distributed to 798 US women neurologists through a closed Facebook group. Of the 181 women who responded ( $22.7 \%$ response rate), $42.6 \%$ reported symptoms of burnout. Independent predictive factors were "working in a high stress environment, lack of control over the work schedule, a higher number of hours at work, and self-reported gender discrimination." 6 The authors invited readers to consider their findings in light of a predicted neurology workforce shortage in the future. For example, $76.6 \%$ of respondents reported perceived gender-based discrimination at their current workplace and $>35 \%$ of respondents were neutral to dissatisfied with their current job with $32 \%$ reporting a moderate to high likelihood of leaving their current job within the next 2 years. More than $46 \%$ would consider reducing their clinical hours, and of those considering reducing their clinical hours $>75 \%$ were interested in spending more time with their families. If given the chance to do it over again, $>20 \%$ of respondents would probably or definitely not want to become a physician again, and of those respondents who would still want to become a physician almost $20 \%$ would probably or definitely choose a different specialty. Furthermore, less than half of respondents $(32 \%-42 \%)$ with one or more children said that they would become a physician again if they had the opportunity, and two-thirds of respondents who had three or more children would not choose the specialty of neurology again. Workload demands and concerns about professionalism, including gender discrimination, were consistent themes. Notably, a majority of women neurologists responding (nearly 60\%) did not follow a regular exercise routine.

These results are concerning, and leaders in neurology have an opportunity to analyze historical gender equity efforts, or lack thereof, and consider them in light of the growing body of literature documenting the specialty's problems with pay equity, authorship, recognition awards, promotion, parity on journal editorial boards, and more..$^{2,7-12}$ No longer can leaders say, "I didn't know." Neurology workforce gender equity studies are available for leaders to review, the data are compelling, and highly qualified women in the field lack equitable pay, career advancement opportunities, and a satisfactory work-life balance. The time to act urgently is now.

Medical societies often set the tone for specialties and introduce medical students and other trainees to the science and values of the field, and so I would recommend getting two houses in equitable order as soon as possible: (1) professional societies that women in neurology and their employers financially support and (2) journals that are affiliated with these societies and benefit from the financial support provided by women in the specialty. There is no doubt that pay and promotion are at the top of the priority list for all workforce gender equity efforts; however, particularly for those in academia, pay and promotion are closely tied to accomplishments at the medical society level and publication in journals. Therefore, if neurologists want to come from behind and lead the way in gender equity, leaders must do what those in other specialties have already done and even more. They must consider both the culture of their specialty

Department of Physical Medicine and Rehabilitation, Harvard Medical School, Spaulding Rehabilitation Hospital, Massachusetts General Hospital, Brigham and Women's Hospital, Boston, Massachusetts. 
and the culture at the institutions ${ }^{13,14}$ in which their ranks work-focusing on both micro-inequities ${ }^{15}$ and macroinequities. Because neurology has been cited in the literature as having journal editorial board ${ }^{9}$ and authorship ${ }^{12}$ disparity issues, the initial step would be aimed at demonstrating a genuine commitment to equity: achieve parity on neurology journal editorial boards. ${ }^{16}$ Second, societies must examine inclusion data for a set of society-level metrics and publish the results as well as an action plan as my colleagues and I have done at the Association of Academic Physiatrists. ${ }^{17}$

Importantly, the path to equity requires the analysis of a comprehensive set of metrics on an ongoing basis. Diversity committees and task forces may direct or support these efforts, but "diversity structures" themselves may actually make things worse, not better, if leaders believe that equity is being addressed when there is no equity data or the data do not actually support those assumptions. ${ }^{18}$ Therefore, successful committees or task forces should be charged first with data analysis and second with developing strategies to close gaps. As such, they require financial and other support from organizational leaders. However, documented and anecdotal evidence suggest that these diversity structures have been underused, ${ }^{19}$ underfunded, and undervalued. To determine the value of equity efforts within an organization, one might compare the diversity-related budget to that allocated for the presidential reception at an annual conference. As Moore et al. ${ }^{6}$ point out, the AAN now has a women's task force. What if the task force had the same budget every year as the president's reception? For the AAN, this would mean that the same amount of money that is allocated every year to honor one person (usually a man), is also reserved to drive the achievement of equity for all of the society's women.

Whatever neurologists decide to do about addressing their gaps in workforce gender equity will be interesting to follow. My money is on this group of intellectual physicians who are trained to solve complex problems. I think neurology may be that dark horse specialty that surprises people by coming from behind to lead the way in workforce gender equity. Equity researchers are investigating, the progress will be documented, and the world will be watching.

\section{Author Disclosure Statement}

No competing financial interests exist.

\section{References}

1. Graves JS, Brashear A. Gender bias in American Academy of Neurology recognition awards? Neurology 2018;91: 291-292.

2. Silver JK, Bank AM, Slocum CS, et al. Women physicians underrepresented in American Academy of Neurology recognition awards. Neurology 2018;91:e603-e614.

3. Bernat JL. How can neurologists avoid burnout? Neurology 2017;88:726-727.

4. Busis NA, Shanafelt TD, Keran CM, et al. Burnout, career satisfaction, and well-being among US neurologists in 2016. Neurology 2017;88:797-808.
5. Sigsbee B, Bernat JL. Physician burnout: A neurologic crisis. Neurology 2014;83:2302-2306.

6. Moore LR, Ziegler C, Hessler A, Singhal D, LaFaver K. Burnout and career satisfaction in women neurologists in the U.S. J Womens Health 2019;28:515-525.

7. McDermott M, Gelb DJ, Wilson K, et al. Sex differences in academic rank and publication rate at top-ranked US Neurology Programs. JAMA Neurol 2018;75:956-961.

8. Weeks WB, Wallace AE. The influence of provider sex on neurologists' annual incomes. Clin Neurol Neurosurg 2007; 109:38-44.

9. Amrein K, Langmann A, Fahrleitner-Pammer A, Pieber TR, Zollner-Schwetz I. Women underrepresented on editorial boards of 60 major medical journals. Gend Med 2011;8:378-387.

10. Grisham S. Medscape physician compensation report 2017. WebMD LLC, 2017. Available at: https://www.medscape .com/slideshow/compensation-2017-overview-6008547\#1 Accessed October 10, 2017.

11. Second Annual Physician Compensation Report, March 2018. Doximity, 2018. Available at: https://www.doximity .com/careers/compensation_report?_csrf_attempted=yes Accessed December 7, 2018.

12. Pakpoor J, Liu L, Yousem D. A 35-year analysis of sex differences in neurology authorship. Neurology 2018;90:472-475.

13. Carr PL, Gunn CM, Kaplan SA, Raj A, Freund KM. Inadequate progress for women in academic medicine: Findings from the National Faculty Study. J Womens Health (Larchmt) 2015;24:190-199.

14. Carr PL, Raj A, Kaplan SE, Terrin N, Breeze JL, Freund KM. Gender differences in academic medicine: Retention, rank, and leadership comparisons from the National Faculty Survey. Acad Med 2018;93:1694-1699.

15. Silver JK, Rowe M, Sinha MS, Molinares DM, Spector ND, Mukherjee D. Micro-inequities in medicine. PM R 2018; 10:1106-1114.

16. Dickersin K, Fredman L, Flegal KM, Scott JD, Crawley B. Is there a sex bias in choosing editors? Epidemiology journals as an example. JAMA 1998;280:260-264.

17. Silver JK, Cuccurullo SJ, Ambrose AF, et al. Association of academic physiatrists Women's Task Force Report. Am J Phys Med Rehabil 2018;97:680-690.

18. Kaiser CR, Major B, Jurcevic I, Dover TL, Brady LM, Shapiro JR. Presumed fair: Ironic effects of organizational diversity structures. J Pers Soc Psychol 2013;104: 504-519.

19. Peek ME, Wilson SC, Bussey-Jones J, et al. A study of national physician organizations' efforts to reduce racial and ethnic health disparities in the United States. Acad Med 2012;87:694-700.

Address correspondence to: Julie K. Silver, $M D$

Department of Physical Medicine and Rehabilitation Massachusetts General Hospital 55 Fruit Street Boston, MA 02114

E-mail: julie_silver@hms.harvard.edu 